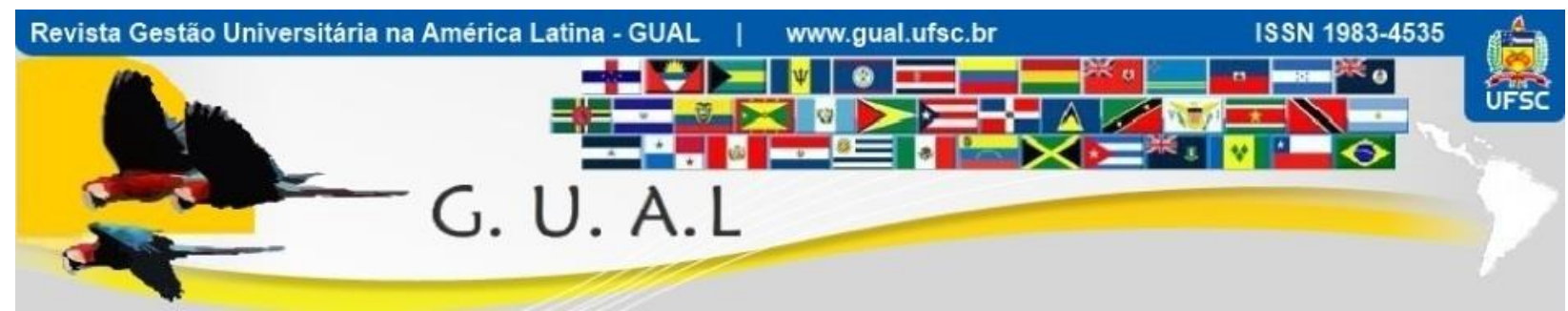

DOI: http://dx.doi.org/10.5007/1983-4535.2014v7n3p93

\title{
CONCILIANDO ADMINISTRAÇÃO DE PROJETOS COM PLANEJAMENTO ESTRATÉGICO NA GESTÃO DE UNIVERSIDADES FEDERAIS BRASILEIRAS
}

\author{
CONCILIATING MANAGEMENT PROJECTS WITH STRATEGIC PLANNING IN \\ MANAGEMENT OF THE BRAZILIAN FEDERAL UNIVERSITIES
}

Julio Eduardo Ornelas Silva, Doutorando Universidade Federal de Santa Catarina - UFSC julioornelas@yahoo.com.br

Daniel Kurten Seemann, Graduando Universidade Federal de Santa Catarina - UFSC danielkseemann@gmail.com

Michelle Bianchini de Melo, Doutoranda Universidade Federal de Santa Catarina - UFSC chelymelo@gmail.com

Cláudio José Amante, Doutor Universidade Federal de Santa Catarina - UFSC claudiojosea@yahoo.com.br

Alexandre Moraes Ramos, Doutor Universidade Federal de Santa Catarina - UFSC amrrms@gmail.com

Gabriela Tavares da Silva, Graduanda Universidade Federal de Santa Catarina - UFSC gabriela.tds@hotmail.com

Recebido em 11/março/2013

Aprovado em 16/junho/2014

Sistema de Avaliação: Double Blind Review 


\title{
RESUMO
}

O planejamento estratégico é um meio pelo qual uma organização define o seu futuro, indicando os meios para se chegar aos objetivos e conquistar a visão pretendida. A sua prática contribui para o autoconhecimento institucional, e proporciona mudanças na condução das suas práticas de modo a trazer efetividade e estratégia. Um bom planejamento exige que sua elaboração seja conduzida de maneira correta, e a administração de projetos pode contribuir no processo de elaboração, por possuir diretrizes sistemáticas com início, meio e fim. $\mathrm{O}$ presente artigo tem por objetivo verificar se a construção dos planejamentos estratégicos de universidades federais brasileiras apresentam características da administração de projetos. Para responder ao objetivo, foram realizadas entrevistas in loco com gestores de universidades federais que participaram do processo de elaboração do planejamento estratégico de suas instituições. Os resultados indicam que os planejamentos são estratégicos e que seus escopos possuem muitas características da administração de projetos, no entanto, a condução do processo, ou os meios, são divergentes, acarretando dificuldades na aceitação e implementação do planejamento estratégico institucional.

Palavras-chave: Planejamento Estratégico. Administração de Projetos. Universidades.

\begin{abstract}
trategic planning is a way by which an organization defines its future, indicating the means to reach goals and achieve the desired vision. Its practice contributes to the institutional selfknowledge, and allows changes in the conduct of their practices in order to bring effectiveness and strategy. A good planning requires that its preparation must be conducted properly, and project management can contribute in the development process by having systematic guidelines that constitutes a beginning, middle and end. This paper aims to verify that the construction of the strategic planning of the Brazilian federal universities have characteristics of project management. To meet the objective, interviews were conducted onsite with managers of federal universities that participated in the drafting of the strategic planning of their institutions. The results indicate that the plans are strategic and their scopes possess many characteristics of project management, however, the conduct of proceedings or the means, are different, resulting in difficulties in the acceptance and implementation of institutional strategic planning.
\end{abstract}

Keywords: Strategic Planning. Project Administration. Universities. 


\section{INTRODUÇÃO}

As gestões profissionais existentes no Brasil não possuem características de planejamento, sendo um resquício da história da sociedade que não está habituada em planejar, agindo no amadorismo e emergencialismo. Nas últimas décadas a realidade está incrementalmente se modificando, sendo que as escolas de gestão estão percebendo a necessidade do planejamento para uma gestão eficaz, contribuindo para posicionar a organização no ambiente em que atua, definir um caminho a percorrer e conquistar a visão pretendida.

As instituições públicas não fogem dessa regra, no qual incluem-se as universidades federais. Os planejamentos estatais até então elaborados constituíam-se apenas para fins orçamentários e patrimoniais, não havendo um caráter estratégico. O fator tende a agravar a situação, ao passo que em universidades, pessoas sem conhecimentos de gestão assumem cargos administrativos. Apesar de serem excelentes doutores em suas áreas, carecem de conhecimentos sobre conduzir uma organização.

Com a mudança de perfil, de modo incremental, a realidade nessas instituições também está se modificando, e planejamentos mais abrangentes começam a aparecer, inclusive estratégicos, sendo que o planejamento estratégico é uma opção consistente de se conduzir uma gestão com efetividade, proporcionando resultados consideráveis aos seus praticantes. Permite que a instituição, e seus gestores, conheçam a organização em que atuam e aonde almejam estar em um horizonte de tempo, delineando os caminhos para se conquistar os objetivos.

A construção do planejamento estratégico é um momento único para organização, tendo início, meio e fim, devendo, entretanto, ser constantemente atualizado após a finalização do documento final, durante a sua implementação. Para a construção do planejamento estratégico, pode-se utilizar a opção de administração de projetos, por possuir características que contribuem para um escopo de planejamento adequado às necessidades institucionais.

Dessa forma, esse artigo resulta de uma pesquisa realizada em universidades federais de todas as regiões do Brasil, que realizaram a construção de um planejamento estratégico. $\mathrm{O}$ objetivo foi verificar se essas construções possuíram características de administração de projetos. Para tanto, o artigo está estruturado nesta introdução, fundamentos teóricos sobre 
planejamento estratégico e administração de projetos, procedimentos metodológicos, resultados e uma seção de discussões e conclusões.

\section{PLANEJAMENTO ESTRATÉGICO}

A ideia de planejamento, conforme Maximiano (2012), começou a ser melhor desenvolvida por Fayol, que entendia como sendo previsão, tendo a incumbência de examinar o futuro e traçar um plano de ação a médio e longo prazo. Pereira (2010, p. 44) fornece um bom entendimento de planejamento quando o difere de seu antagônico:

[...] planejamento difere de improvisar. Enquanto o primeiro está preocupado em elaborar um plano para fazer algo ou mesmo criar um esquema para agir, o segundo prepara algo às pressas no momento em que as coisas acontecem e às vezes age ao acaso.

A atividade de planejamento naturalmente origina decisões presentes tomadas a partir do exame do impacto das mesmas no futuro, dando-lhe o que Oliveira (2008) chama de dimensão temporal de alto significado. A busca é pela redução da incerteza envolvida no processo decisório, e consequentemente, uma maior probabilidade de alcance dos objetivos, metas e desafios delineados pela organização. Dessa forma, segundo o autor, o processo de planejar gera indagações que "[...] envolvem questionamentos sobre o que fazer, como, quando, quanto, para quem, por que, por quem e onde." (2008, p. 5).

O planejamento, de acordo com Oliveira (2008), tem como princípios ser participativo, coordenador, integrado e permanente. Deve ser participativo de modo a ser realizado por todas as áreas pertinentes ao processo. A coordenação deve garantir que os envolvidos atuem interdependentemente. A integração deve garantir que os vários escalões da empresa tenham seus planejamentos integrados. E o planejamento deve ser permanente, para ter utilidade e valor ao longo do tempo, devido à turbulência ambiental.

Três tipos de planejamento são apresentados por Oliveira (2008), considerando os níveis hierárquicos e de decisão de uma empresa, conforme a Figura 1. 


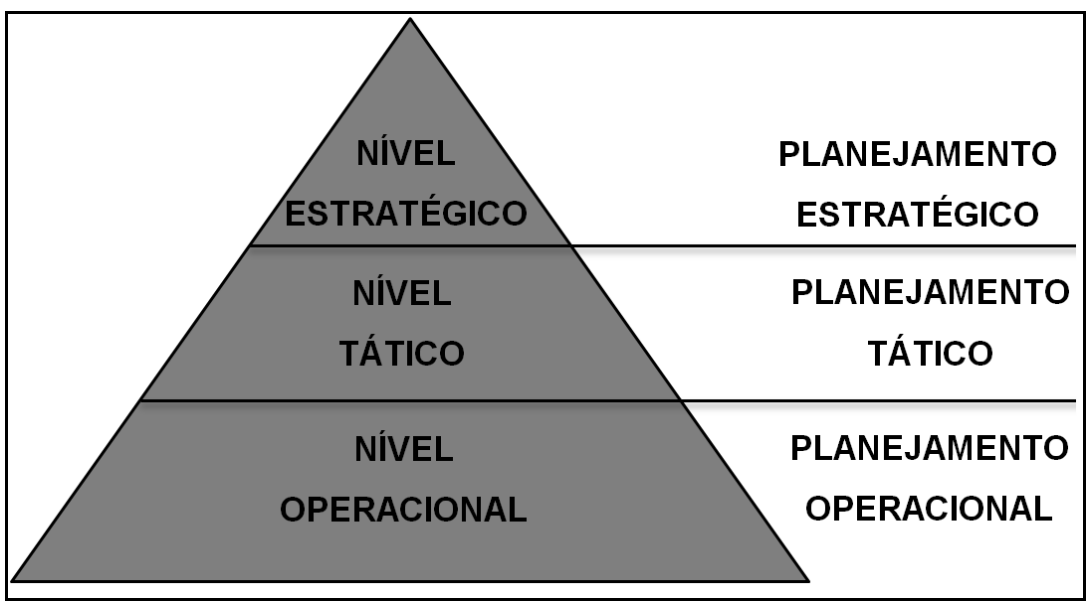

Figura 1 Níveis de decisão e tipos de planejamento Fonte: Oliveira (2008, p. 15).

É nesse raciocínio que aparece o planejamento estratégico, que, segundo Pereira (2010), está vinculado ao nível de decisão mais alto da organização. Para o nível médio, cabem os planejamentos táticos, e para o nível operacional, cabem os planos operacionais.

Compreendido o contexto do planejamento e do planejamento estratégico, detalha-se agora as teorias sobre este segundo. Para Almeida (2010, p. 5), o conceito de "planejamento estratégico é uma técnica administrativa que procura ordenar as ideias das pessoas, de forma que se possa criar uma visão do caminho que se deve seguir (estratégia).”. Após a ordenação das ideias, organiza-se as ações, implementando o plano estratégico para que se caminhe na direção pretendida, sem desperdício de esforços. Na concepção de Pereira (2010, p. 47),

\footnotetext{
planejamento estratégico é um processo que consiste na análise sistemática dos pontos fortes (competências) e fracos (incompetências ou possibilidades de melhorias) da organização, e das oportunidades e ameaças do ambiente externo, com o objetivo de formular (formar) estratégias e ações estratégicas com o intuito de aumentar a competitividade e seu grau de resolutividade.
}

Complementando, Oliveira (2008, p. 4) entende que o "planejamento estratégico corresponde ao estabelecimento de um conjunto de providências a serem tomadas pelo executivo para uma situação em que o futuro tende a ser diferente do passado.”. Para Almeida (2010), o planejamento estratégico não indica como administrar o dia a dia do trabalho, mas mostra como estruturar ações, ajudando os gestores a organizarem suas ideias e direcionar suas ações.

Oliveira (2008, p. 18) lembra que o planejamento estratégico afeta toda a organização, propondo estratégias, objetivos e ações com perspectivas de longo prazo, e que 
é, normalmente, de responsabilidade dos níveis mais altos da empresa e diz respeito tanto à formulação de objetivos quanto à seleção dos cursos de ação a serem seguidos para sua consecução, levando em conta as condições externas e internas à empresa e sua evolução esperada. (2008, p. 18)

As literaturas que tratam de planejamento estratégico propõem etapas para sua operacionalização, todos similares e que caminham para o mesmo objetivo. Para Pereira (2010), o processo da estratégia possui três momentos, sendo o momento do diagnóstico estratégico, o momento da formulação das etapas do processo de planejamento estratégico e o momento da implementação e controle do processo de planejamento estratégico.

O primeiro momento proposto por Pereira (2010) é o diagnóstico estratégico, que visa responder se a organização está preparada para o planejamento estratégico. $\mathrm{O}$ autor sugere que a alta administração da organização responda a duas questões básicas, sendo (1) "Esse é o momento ideal para se desenvolver um Planejamento Estratégico?" e (2) “A alta administração da organização tem consciência que deve se envolver $100 \%$ com o processo do Planejamento Estratégico?"

A resposta do primeiro questionamento deve levar em conta grandes turbulências externas que inviabilizariam o processo, dificuldades financeiras e conflitos internos. No segundo questionando, Pereira (2010) considera se os gestores sabem o que é um planejamento estratégico, além de garantir que se envolverão, não ficando apenas na intenção, sob pena de frustações.

Limitações ou desvantagens sempre são observadas, variando apenas a intensidade, que irá ditar a viabilidade ou não da implantação do planejamento estratégico. Como exemplos citados por Pereira (2010) estão a resistência interna por alguns membros da organização; a capacitação gerencial, frente a dependência de consultor externo; o desafio que é implementar o planejamento, por ser difícil; as limitações do processo; e o dispêndio de tempo e recursos.

As limitações do processo mais comuns para Pereira (2010) são a percepção do resultado negativo; o medo de mais trabalho; a necessidade de mudar hábitos; a falta de comunicação do processo para os membros da organização; a incapacidade de alinhar a organização com o mundo; e a impressão de que os envolvidos estão sendo obrigados a mudar.

O segundo momento, para Pereira (2010, p. 56), é o próprio planejamento estratégico, em que se coloca no papel as etapas do processo, especificamente (1) a declaração de valores, 


\section{CONCILIANDO ADMINISTRAÇÃO DE PROJETOS E PLANEJAMENTO ESTRATÉGICO NA GESTÃO DE UNIVERSIDADES FEDERAIS BRASILEIRAS \\ DOI: http://dx.doi.org/10.5007/10.5007/1983-4535.2014v7n3p93}

(2) a missão, (3) a visão, (4) os fatores críticos de sucesso, (5) a análise externa (oportunidades e ameaças), (6) a análise interna (pontos fortes e fracos), (7) a matriz FOFA, (8) as questões estratégicas, (9) as estratégias e (10) as ações estratégicas.

O terceiro momento é a execução e controle das etapas propostas por Pereira (2010) no segundo momento, com o devido acompanhamento dos resultados alcançados. O autor explica que a implementação é a organização colocar em prática o documento de planejamento estratégico, lançando-o oficialmente entre os membros da organização por diversos canais de comunicação, como um vídeo na intranet, cartazes ou evento de lançamento. Independente do canal, o importante é que as informações alcancem todos os membros.

Com a implementação, surgem a avaliação e o controle, que para Oliveira (2008 p. 55), são etapas que analisam “[...] como a empresa está indo para a situação desejada.”, sendo uma ação que assegura a concretização de objetivos, desafios, metas, estratégias e projetos previamente delineados. Neste ponto utilizam-se muitos indicadores de desempenho, avaliando profissionais, resultados, desvios, e implementando ações corretivas e complementando o planejamento com informações adicionais quando necessário.

Ainda sobre a implementação, Hrebiniak (2006) é contundente em afirmar que as diversas literaturas de gestão, quando tratam de estratégia, abundam em teorias e conselhos de como fazer um bom planejamento, em sua formulação. No entanto, o problema de desempenho deficiente das organizações não está no planejamento, mas na sua realização ou execução. Ou seja, geralmente as estratégias não são implementadas com sucesso. A elaboração da estratégia é um desafio extremo e muito difícil, no entanto, é na execução que se toma maior tempo, no sentido de que fazer o plano funcionar é um desafio maior que criar o próprio plano. Apesar de na realidade haver separação entre as tarefas de planejamento e execução, as duas apresentam grande interdependência, pois o planejamento afeta a execução.

Mas como saber se a organização possui ou implementou corretamente um planejamento estratégico? Oliveira (2008, p. 18) propõe algumas perguntas básicas cujas respostas evidenciam a real existência de um planejamento estratégico, sendo:

- conhece seu negócio? Sabe a real amplitude dele? Conhece as interações com outros negócios?

- tem perfeita interação entre os fatores externos - ou não controláveis - e os fatores internos - ou controláveis em sua empresa?

- conhece a real capacitação de sua empresa? 


\section{CONCILIANDO ADMINISTRAÇÃO DE PROJETOS E PLANEJAMENTO ESTRATÉGICO NA GESTÃO \\ DE UNIVERSIDADES FEDERAIS BRASILEIRAS \\ DOI: http://dx.doi.org/10.5007/10.5007/1983-4535.2014v7n3p93}

- conhece sua vantagem competitiva? E as dos concorrentes? E a vantagem competitiva que o mercado quer comprar?

- a sua empresa tem uniformidade de atuação?

- tem caminhos alternativos para o caso do plano básico não dar certo?

- todos na empresa têm entendimento e comprometimento para com os resultados esperados?

- todos têm acompanhamento e avaliação dos resultados em tempo real?

Diante do exposto pelas literaturas, observa-se que a implementação do que foi planejado também necessita de atenção especial. Tanto para a elaboração quanto para a implementação do planejamento, apresenta-se a administração de projetos como alternativa de ferramenta de suporte, cujos conceitos são apresentados na sequência.

\section{ADMINISTRAÇÃO DE PROJETOS}

Newton (2011) entende que concomitante a elaboração de novos serviços, produtos ou mesmo funções de gestão nos variados tipos de organizações, a concretização do planejamento das atividades e ações deve ser pensada em função de projetos, ou mais especificamente, em administração de projetos. O planejamento, na visão de Consalter (2011, p. 18), nada mais é do que um requisito primário e elementar na administração, consistindo em determinar ações a serem desempenhadas e procurar antecipar o que deve ser feito no futuro. "O planejamento consiste na ordenação sistemática da conduta para a consecução de determinados propósitos.”. Para o autor, o processo do planejamento é fundamental ao gerenciamento de projetos, pois são definidas as entregas, a especificação do escopo, o orçamento, o cronograma, o detalhamento das atividades, habilidades e recursos necessários para concretização do projeto pretendido.

Newton (2011) define projeto como uma forma básica de organização e modo de trabalho, que estrutura pessoas e atividades de maneira ordenada e eficiente, caracterizando um estilo de coordenação e gestão do trabalho que se diferencia de outros modos de gestão por ser focado em resultados específicos estabelecidos preliminarmente, e que quando alcançados, finaliza o projeto. Valeriano (2005) afirma que organizações só executam dois tipos de trabalho, sendo (1) as atividades rotineiras e repetitivas, identificadas como operações correntes, e (2) atividades temporárias, identificadas como projetos, sendo um empreendimento com duração temporária e realizado para criar um produto singular. Para o autor (2005, p. 9), 
O produto tem um tempo prefixado para ser concluído e seu resultado ou novo serviço (um novo processo administrativo ou um novo curso de treinamento, por exemplo). Os bens ou serviços que foram concebidos e gerados por projeto serão repetidamente reproduzidos por operações correntes: a linha de produção do medicamento ou do celular e o exercício da nova atividade administrativa ou das atividades didáticas do novo curso.

Lima (2010) corrobora com a ideia apresentada ao definir que projeto pode ser entendido como um empreendimento único e não repetitivo, cujo objetivo é a criação de um novo produto ou serviço, e constituído de um processo que tem início, meio e fim, organizado e estruturado a fim de cumprir objetivos predefinidos. O autor detalha que

Projeto é um processo único, consistindo de um grupo de atividades coordenadas e controladas com datas para início e término, empreendido para o alcance de um objetivo conforme requisitos específicos, incluindo limitações de tempo, custo e recursos. (Lima, 2010, p. 46)

Outro conceito apontado por Lima (2010, p. 4) origina do Project Management Institute - PMI, que indica um projeto como sendo "um empreendimento temporário, planejado, executado e controlado, com objetivo de criar um produto ou serviço único.”. A administração de projetos é regulada por certificados emitidos por instituições profissionais, conforme Valeriano (2005), na qual a International Project Management Association - IPMA possui abrangência internacional, fundada em 1967 na Suíça, e que a cada gestão muda o local de sua sede. No Brasil, a seção regional denomina-se Associação Brasileira de Gerenciamento de Projetos - ABGP. Nos Estados Unidos é conhecido por Project Management Institute - PMI, fundado em 1969.

A percepção da necessidade de realização e construção de projetos, segundo Valeriano (2005), pode ser explicada a partir dos vários estímulos que fatores isolados podem ter, como legislações ou expansão da instalação, ou solicitações e ofertas de um novo produto ou serviço, os quais podem ser externas ou internas à organização. Newton (2011) acrescenta que todo projeto é feito para alguém ou algum grupo de pessoas, em geral, os clientes.

A decomposição de um projeto em diversas etapas é uma questão importante a ser salientada, no qual Valeriano (2005) indica que contribui para que o desempenho e implementação sejam feitos da maneira mais eficiente possível. Inicialmente, o serviço ou produto é decomposto em partes constitutivas e em possíveis custos e recursos que seriam utilizados. O gerenciamento é planejado e executado de acordo com as áreas de interesse gerenciais, como o escopo do projeto, seus custos, tempo, qualidade, pessoas envolvidas e equipes. Para o autor, o processo de um projeto geralmente contempla: 


\section{CONCILIANDO ADMINISTRAÇÃO DE PROJETOS E PLANEJAMENTO ESTRATÉGICO NA GESTÃO \\ DE UNIVERSIDADES FEDERAIS BRASILEIRAS \\ DOI: http://dx.doi.org/10.5007/10.5007/1983-4535.2014v7n3p93}

- Iniciação: Processos que compreendem o estímulo à autorização do projeto;

- Planejamento: Momento em que se estabelece o que fazer, como, quando, por quem, por quanto, em quais condições e outras definições;

- Execução: Etapa em que se realiza o que foi previamente planejado;

- Monitoração e controle: Etapas em que a execução é acompanhada ou monitorada e, se necessário, ajustada ao plano (também há a possibilidade da necessidade de se proceder a ajustes no plano);

- Encerramento: O projeto é formalmente concluído junto aos clientes.

Entretanto, Oliveira (2010) sugere que deve-se ter consciência que em determinadas situações, os processos podem ocorrer de maneira não linear, a depender do ciclo de vida do projeto, dos serviços/produtos gerados e de possíveis solicitações de mudanças nos objetivos, processos em si, prazos e outras variáveis. Na sequência, são descritos com maior detalhamento, as etapas propostas por Valeriano (2005), com contribuições de outros autores.

\subsection{INICIALIZAÇÃO E CONCEPÇÃO DO PROJETO}

A caracterização da fase de iniciação proposta por Valeriano (2005) é a do começo do projeto, a partir de um conjunto de percepções, vontades e interesses que estimula uma demanda ou necessidade oriunda de entidade externa, ou mesmo por uma oferta ou oportunidade com origem na própria organização ou grupo que empreenderá o projeto. São identificadas necessidades e oportunidades que precisam ser supridas, identificado o problema na sua concepção e então definindo comprometimentos da organização que estimam a aproximação dos esforços a serem despendidos, principalmente em termos de recursos necessários, estimativas de custos e prazos para dar base à autorização do projeto.

Nesta fase, Lima (2011) complementa sobre a necessidade da criação do plano sumário, documento que formaliza o projeto, com a autorização e aquisição de poderes dentro da organização, de forma que a equipe do projeto tenha autonomia para utilizar quaisquer recursos disponíveis e relacionados a sua execução. O documento deve conter, de maneira clara e detalhada, a descrição do produto ou serviço, seu motivo e finalidade ao qual se destina, bem como a justificativa que originou a necessidade do projeto.

\subsection{PLANEJAMENTO}

Com base nas informações compiladas na fase de iniciação, procede-se ao planejamento, que estabelecerá de forma progressiva o escopo do projeto. De acordo com Valeriano (2005), neste momento são definidas todas as atividades que envolvam a utilização 


\section{CONCILIANDO ADMINISTRAÇÃO DE PROJETOS E PLANEJAMENTO ESTRATÉGICO NA GESTÃO \\ DE UNIVERSIDADES FEDERAIS BRASILEIRAS \\ DOI: http://dx.doi.org/10.5007/10.5007/1983-4535.2014v7n3p93}

dos recursos, com a explicação dos produtos e serviços, de seus requisitos e destino, além dos diversos processos técnicos e administrativos, dos compromissos internos preestabelecidos e também a definição da equipe de trabalho.

Lima (2010) acrescenta que na fase do planejamento de um projeto, deve-se analisar o cenário de comportamento dos custos, do cronograma e da qualidade ao longo da execução, transformando-se em base de avaliação de desempenho que refletirá na realização de todas as demais etapas, e permitirá fazer comparações de como devem ser executadas as ações planejadas, com quem fazer e quando fazer.

\subsection{EXECUÇÃO}

A fase da execução, segundo Valeriano (2005), coloca em ação todas as tarefas planejadas, nas condições, custos, prazos e qualidade com as quais foram previamente planejadas. É caracterizada por um intenso trabalho em equipe, sob a coordenação geral de um gerente de projeto. Os resultados da execução devem ser documentados para fornecer os registros relevantes entre pessoas, ideias e informações necessárias para o andamento e sucesso do projeto como um todo. A equipe envolvida deve estar preparada para enviar e receber comunicações e compreender como a sua comunicação afeta o projeto como um todo. Lima (2010) complementa que o resultado será tão eficiente e expressivo quanto melhor for feito as fases da iniciação e planejamento, pois espera-se que ocorram menos problemas e retrabalhos durante esta etapa. Até que os resultados apareçam, diversas tensões e problemas podem emergir, o que é comum, em especial a relação entre patrocinador e demais membros.

Os recursos necessários, seja equipamentos, materiais, serviços ou pessoal, devem ser propriamente alocados, em especial o que tange ao pessoal, uma vez que, segundo Lima (2010), estes serão redistribuídos temporariamente de uma área para a execução do projeto, sendo portanto, ponto crítico para o autor. É essencial que o plano de ações torne o projeto uma realidade, dentre as quais destaca-se a verificação do escopo, a garantia da qualidade com padrões previamente estabelecidos, a distribuição da informação, a solicitação de material, a seleção de fornecedores, bem como a administração de contratos, que dará seguridade jurídica perante os fornecedores, ao cumprir o que foi acordado no contrato. 


\subsection{CONTROLE}

A fase de monitoração e gerenciamento é também conhecida como a fase de controle do projeto, segundo Valeriano (2005), na qual diversas modificações e ajustes evidenciam-se como necessárias, incidindo diretamente sobre o escopo desejado. Para Lima (2010), o controle se dá em todas as etapas do projeto, porém, há uma ênfase maior na etapa posterior à execução, sendo que o primeiro passo é identificar o que deve ser monitorado para a avaliação do desempenho e o alcance dos objetivos estabelecidos previamente, e à medida que possíveis distorções e variações apareçam, busca-se intervir na execução, realizando modificações suficientes para reenquadrar os objetivos do projeto. As intervenções e modificações devem ser investigadas pelo gestor de projetos, sempre com vistas a identificar as causas dos desvios que geraram ações corretivas eficientes.

O controle, na visão de Lima (2010) apresenta-se sob duas formas, com naturezas distintas, e que posteriormente indicará uma metodologia adequada de correção, sendo o controle reativo, quando já ocorreram variações ou desvios em relação ao planejado e faz-se necessário gerar ações corretivas, e os controles proativos, em que gera-se ações preventivas para evitar que aconteçam desvios ou variações em relação ao que foi planejado.

\subsection{ENCERRAMENTO}

Concretizado o objetivo do projeto, Valeriano (2005) explica que o projeto em si deverá ser encerrado, devendo ser tomadas todas as providências necessárias, como a conclusão de contratos, o encerramento administrativo, a devolução de materiais, pessoas e espaços utilizados, sendo que antes da dissolução da equipe, deverá ser feita uma avaliação geral e levantamento dos pontos que possam melhorar em um futuro projeto. Lima (2010) possui a mesma compreensão, acreditando ser importante tomar notas do aprendizado, por meio de reuniões e registrados de todas as informações para uso posterior e aproveitamento em outros projetos. $\mathrm{O}$ autor recomenda a criação de um relatório de conclusões com base nas documentações de medida de desempenho, do produto/serviço e da memória do projeto em si, contribuindo para que o patrocinador aceite formalmente o produto final. (Lima, 2010)

\section{PROCEDIMENTOS METODOLÓGICOS}

A pesquisa caracteriza-se como monográfica, também denominada como estudo de caso, consistindo, segundo Cruz e Ribeiro (2003, p. 36) "no estudo de determinados 


\section{CONCILIANDO ADMINISTRAÇÃO DE PROJETOS E PLANEJAMENTO ESTRATÉGICO NA GESTÃO \\ DE UNIVERSIDADES FEDERAIS BRASILEIRAS \\ DOI: http://dx.doi.org/10.5007/10.5007/1983-4535.2014v7n3p93}

indivíduos, profissões, instituições, condições, grupos ou comunidades, com a finalidade de obter generalizações.”. Dessa forma, contribui significativamente para que as conclusões sejam realistas e possam ser generalizadas pelo método indutivo. Realizou-se estudos de caso múltiplos, por analisar oito universidades federais, ou oito casos, buscando ênfase na análise das contribuições do Planejamento estratégico e do plano de desenvolvimento institucional para a gestão dessas universidades, seguindo o que sugere Gil (2010, p. 37), de proceder um “[...] estudo profundo e exaustivo de um ou poucos objetos, de maneira que permita seu amplo e detalhado conhecimento.".

Cervo, Bervian e Silva (2007, p. 32) também classificam uma pesquisa por tipo de estudo, onde este trabalho enquadra-se como um estudo descritivo. No estudo descritivo, o pesquisador observa, registra, analisa e correlaciona fatos ou fenômenos sem manipulá-los. Segundo o autor, “[...] é necessário que o resultado da observação seja cuidadosamente registrado, processo que configura a técnica científica da descrição.”. As entrevistas nas oito universidades analisadas apenas descrevem as suas realidades, não havendo intenção de modifica-las a fim de observar outros possíveis resultados.

Outra classificação da pesquisa é por utilizar uma metodologia qualitativa, que de acordo com Pereira (2004, p. 21), “é uma estratégia de classificação de um fenômeno aparentemente imponderável que, fixando premissas de natureza ontológica e semântica, instrumentaliza o reconhecimento do evento, a análise de seu comportamento e suas relações com outros eventos.". Lakatos e Marconi (2010, p. 273) complementam ao afirmarem que "a metodologia qualitativa tradicionalmente se identifica com o estudo de caso.” e cujas "[...] técnicas fundamentais de coleta de dados são: observação, entrevista e história de vida." (2010, p. 275).

Nessa lógica dos autores, pode-se afirmar que esta pesquisa atende aos aspectos apresentados para ser classificada como qualitativa, pois:

- a análise das oito universidades é um estudo de oito casos;

- a coleta de dados utiliza-se de entrevistas;

- inicia com um problema social aplicado; e

- contempla interpretações do pesquisador quanto aos dados coletados, sem tratamento estatístico.

Foram selecionadas oito instituições para análise, sendo: 
-Universidade Federal de Alagoas - UFAL;

-Universidade Federal do Amapá - UNIFAP;

-Universidade Federal da Grande Dourados - UFGD;

-Universidade Federal do Maranhão - UFMA;

-Universidade Federal de Minas Gerais - UFMG;

-Universidade de Brasília - UnB;

-Universidade Federal do Pará - UFPA; e

-Universidade Federal de Santa Catarina - UFSC.

Considerando os critérios utilizados para a escolha dessas universidades, enquadra-se a seleção de modo intencional para Creswell (2010), amostragem por julgamento, segundo Santos (2012), ou amostragem não-probabilística, conforme Diehl e Tatiam (2004), pois fez parte de um projeto de pesquisa aprovado e financiado pela Capes, e cujos objetivos consideraram universidades federais brasileiras em todas as regiões do Brasil.

As entrevistas ocorreram com membros investidos formalmente em cargos pelo dirigente máximo, que são os pró-reitores das pró-reitorias de planejamento, coordenadores e diretores lotados nessas pró-reitorias ou órgãos congêneres. Em algumas universidades os vice-reitores também foram entrevistados, cujos dados contribuíram para responder o objetivo proposto. As entrevistas gravadas e sua transcrição foram realizadas no segundo semestre de 2012 e primeiro semestre de 2013, com visita in loco nas universidades, sendo que as viagens até as instituições foram financiadas pelo projeto supracitado.

Ainda em relação às entrevistas, buscou-se respaldar os entrevistados sobre quaisquer consequências de sua fala, possuindo um caráter ético, bem como permitiu conforto ao gestor, garantindo que ao explanar sua percepção da realidade, inclusive os aspectos negativos, sua identificação estaria protegida. As denominações que são encontradas nos resultados da presente pesquisa são do alfabeto grego, como alfa, beta e gama.

Feito a coleta de dados das entrevistas, seguiu-se para as transcrições das mesmas, textualizando as falas dos entrevistados. As informações foram reorganizadas e associadas ao objetivo proposto, para então proceder interpretações à luz das literaturas utilizadas na fundamentação teórica. Nessa forma de análise de dados, na denominação de Severino (2007, p. 59), parte-se da compreensão objetiva da mensagem comunicado pelo texto, seguindo para a síntese das ideias do raciocínio e a compreensão profunda do texto. Segundo o autor, a interpretação verifica "[...] como as ideias expostas se relacionam com as posições gerais do pensamento teórico.”. Finalizadas, foram elencadas na seção dos resultados, para gerar as conclusões. 


\title{
5 RESULTADOS
}

A efetividade de um planejamento ocorre quando a sua construção e implementação são corretamente conduzidas, e para que isso ocorra, autores recomendam certos rituais a serem seguidos, conforme os apresentados nas seções sobre planejamento estratégico e administração de projetos. Por meio das entrevistas realizadas nas universidades pesquisadas, é possível identificar se essas recomendações fizeram parte da construção dos planejamentos, informações que são expostas nesta seção. Observa-se pelos resultados que o processo de construção do planejamento estratégico é atípico, por ser temporário, tendo início, meio e fim, para então, implementar as ações delineadas.

O início do processo de construção dos planejamentos são semelhantes entre as universidades pesquisadas, partindo da administração central a iniciativa de condução do processo, em geral, alguma pró-reitoria, coordenadoria ou diretoria relacionada ao planejamento, cujos funcionários se mobilizam e iniciam o levantamento dos procedimentos necessários. $\mathrm{O}$ reitor da instituição nomeia uma comissão que conduz todo o processo. $\mathrm{O}$ entrevistado 4 relata esse acontecimento na Universidade Gama:

\begin{abstract}
Montamos a comissão escolhendo representantes de todas essas áreas. Então o reitor baixa uma portaria para que essa comissão inicie os trabalhos. A comissão se subdivide ao longo dos trabalhos, e então surge a subcomissão que trabalha a política de graduação, a subcomissão que trabalha a política de ensino de graduação, a subcomissão que trabalha a política de ensino de pós-graduação, a subcomissão que trabalha a questão da inovação e da pesquisa e do empreendedorismo, a subcomissão que trabalha a parte de assistência estudantil, a subcomissão de extensão. Surge uma série de subcomissões, em que são baixadas portarias também. Essas subcomissões vão crescendo, agregando mais pessoas para a base delas, e então vão construindo a primeira minuta.
\end{abstract}

Na Universidade Ômega também houve a criação de uma comissão multi setorial. A administração central enxergou a necessidade de construção do PDI para além da exigência legal, montando uma comissão com representantes das pró-reitorias e unidades de ensino, sendo que a equipe da pró-reitoria de planejamento foi a responsável pela pró-atividade em fazer o PDI se concretizar.

Designadas as comissões, as etapas seguintes diferem entre as universidades. Há situações em que o processo envolve a participação da comunidade universitária. $\mathrm{O}$ entrevistado 3, da Universidade Beta, citou:

Tendo essa necessidade institucional, a reitoria criou uma grande comissão, da qual eu fui coordenador. Nós chamamos uma pessoa já experiente, que era Pró-Reitor de Planejamento de outra universidade. Ele veio nos dar uma orientação de como 
construir esse PDI. Nessas orientações participava toda a administração central e mais um conjunto grande de professores, técnicos e alunos. E depois isso partiu para discussões temáticas dentro de toda a universidade, grande seminários, onde se construiu um grande documento e esse documento foi levado ao conselho universitário e aprovado.

Na Universidade Ômega, a comissão proferiu palestras, workshops e diversas reuniões com os membros da comunidade acadêmica para a elaboração do PDI, com a conscientização do que era o documento. Cada unidade era responsável por coletar as informações de seus setores, e normalmente delegado a mais de um responsável, mas sempre encabeçado pelo dirigente. Após as reuniões setoriais, o plano tinha que ser aprovado por cada colegiado, e então encaminhado à equipe da pró-reitoria de planejamento, que após as devidas correções, foi aprovado no Conselho Universitário.

Em outros casos, os gestores relatam que apesar da iniciativa da comissão para que houvesse participação na construção do PDI, o mesmo não ocorreu, acarretando dificuldades na aprovação do documento. É o caso da Universidade Delta, informado pelo entrevistado 5:

O processo de construção do PDI foi democrático. Foi feita a comissão, nós fizemos as consultas e não tivemos grandes participações nas contribuições. Colocamos disponível urna, criamos link para contribuições, só que vieram pouquíssimas. Então construímos através dessa comissão, e na hora da aprovação, que nós tivemos a aprovação do documento final, aí apareceram algumas pessoas, naquele caso "ah não foi construído democraticamente". Foi para o conselho universitário, e no conselho não conseguimos aprovar, ficou enrolando pois eles queriam a construção de um novo.

Quando o entrevistado 5 da Universidade Delta foi indagado em outro momento se a construção do PDI foi divulgada aos membros da comunidade universitária, verificou-se que as razões da baixa participação estavam no escopo do meio de comunicação entre a comissão e a comunidade. $\mathrm{O}$ entrevistador 5 relatou:

Foi divulgado tanto na comunidade docente, discente quanto os técnicoadministrativos. Foi através do site, foi criado um site e sempre colocavam alguns links na página principal da universidade.

Na Universidade Alfa, a construção do PDI restringiu-se aos dirigentes, e somente após elaborado, é que o plano foi divulgado aos membros da comunidade universitária, para então seguir para aprovação no conselho superior. O entrevistado 2 expõe esse fato:

Nós tomamos o anterior como ponto de partido, que estava em vigor. Num primeiro momento fizemos reuniões com os diversos órgãos da universidade. Na verdade lembrá-los dos prazos, cronogramas. Fizemos também reuniões com os diretores das unidades para coloca-los a par da situação. Demos um prazo para que esses diversos setores, pró-reitorias, encaminhassem sugestões. Nós fizemos um primeiro 
documento preliminar, voltamos para cada um dos órgãos. Eles fizeram modificações, fizemos uma discussão sobre esse documento preliminar e estamos agora numa terceira rodada. Estamos para soltar, esse mês, um documento já mais consolidado, que será, de certa maneira, o que será divulgado. Estamos fazendo pequenos ajustes, mas até o final desse mês nós vamos reencaminhar para cada um: "Olha aqui, estão aqui os resultados das nossas discussões anteriores com o que conseguimos consolidar". Acho que no segundo semestre nós queremos publicar. A ideia é publica um livro com isso. Um livro que vai ser distribuído, que vai ser divulgado para o conjunto da comunidade. Com prazos, um calendário de discussões que lá na frente encaminhe para uma aprovação formal pelo conselho universitário.

A Universidade Sigma elabora seu PDI por meio de questionários respondidos pelas áreas competentes, conforme informado pelo entrevistado 8:

Como é que tem sido feito: primeiro é feito um levantamento de ambiente pra ter uma noção de como está a situação operacional do Estado. Nosso foco foi o Estado e o papel que a Universidade Sigma desempenha nesse contexto. A partir daí, foi feito um questionário, uma planilha de forma de como cada uma das 5 ou 6 áreas chegarão às suas metas descritas no próprio PDI. "Olha lá professor, o senhor disse que em 2010 ou 2011 nós tínhamos aqui trigo, 2015 nos vamos poder chegar a Fubá, como é que vamos fazer, e quem vai fazer.". Será desmembrada as formas com que os objetivos serão alcançados, então esses questionários foram enviados para cada uma das áreas pertinentes, quando esses questionários voltarem, então serão compilados e a partir daí esse plano estratégico vai estar pronto, só a questão de uma conclusão.

Na Universidade Zeta, o PDI não foi participativo, ou seja, ficou restringido a um grupo de pessoas devido a preocupação em elaborar um documento para cumprir a legislação em tempo. Assim, o entrevistado 7 explicou que

Com relação ao PDI, ele foi um pouco mais corrido, na verdade ele não foi assim tão participativo, pois faltou tempo, e precisávamos publicar, e ele não foi publicado. Meio que pegando algumas informações, só que em reuniões informais, construindo o documento. Consultou-se outros elementos, algumas outras publicações, como por exemplo os relatórios de auto avaliação que também dão um diagnóstico de algumas previsões do que se pretende fazer em termos de graduação, de pesquisa, de pósgraduação, de extensão, de parte da gestão de finanças e orçamentárias, da gestão administrativa da universidade. E aí como foi preciso fazer isso, a gente não teve um processo tão participativo.

No entanto, mesmo o planejamento estratégico que estava em elaboração com antecedência na Universidade Zeta, não foi participativo, apesar de poder se constituir um planejamento estratégico por possuir todos os itens sugeridos por Pereira (2010). O entrevistado 7 explanou como se deu esse processo:

A secretária de planejamento na época, convidou a alta administração, que no caso foi o reitor, o vice-reitor, todos os pró-reitores e diretores de unidades que considerávamos mais importantes, como por exemplo o diretor do centro de desenvolvimento tecnológico, a área de gestão de patrimônio imobiliário da Universidade Zeta, que é um patrimônio grande, auditoria, procuradoria jurídica. Então essas unidades chaves dentro da Universidade Zeta foram convidadas com 
assessoria da secretaria de planejamento na época, minha, da equipe, do secretário da época, reunimos em um local e seguindo uma metodologia de uma pesquisadora aqui da Universidade Zeta, elaboramos a missão, a visão, os desafios estratégicos, diretrizes, identificação das diretrizes, objetivos estratégicos, as metas. Então com esse documento voltamos para cá e depois em reuniões com cada uma dessas áreas específicas, foi definindo quais eram os indicadores, apurando as metas. Por exemplo, na área de graduação o pessoal da pró-reitoria de graduação que sentou conosco elaborou uma matriz SWOT, identificou prioridades. Então assim se deu a parte do planejamento estratégico.

Quando se analisa o tempo de abrangência do planejamento estratégico, o entrevistado 3 afirma que na Universidade Beta o documento possui vigência até 2020:

Se nós conseguirmos implementar todo o nosso planejamento estratégico até 2020, nós estaremos entre as grandes universidades desse país. É um planejamento muito austencioso.

Para o entrevistado 8, o planejamento estratégico da Universidade Sigma possui um horizonte de quinze anos. Cabe salientar que o referido planejamento não foi encontrado publicamente. Quanto a periodicidade de atualização, apenas a fala do entrevistado 4, da Universidade Gama, indicou cumprir, para se adaptar ao cenário externo:

\begin{abstract}
Sim, sempre acontece conosco aqui, fizemos a versão dois, a versão três do mesmo PDI, até porque temos essa sistemática de anualmente dar uma revisada no planejamento estratégico. Então, revisamos o planejamento estratégico quando chega alguma demanda nova, nós somos muito ligados às políticas do Ministério da Educação. Então de repente para atingir uma determinada meta do Plano Nacional de Educação, o MEC resolveu colocar um novo programa. Esse novo programa, por exemplo, o REUNI. O REUNI foi uma dessas coisas. Mas tem outras, como o PAFOR, a formação de professores da educação básica, da rede pública. Nós tínhamos um PDI que contemplava a educação a distância, mas não tinha com o formato que precisávamos deixá-lo. Então, quando a universidade se movimenta para algum ponto, e aquilo está tomando uma força tamanha, e enxergamos que aquilo é um fator importante para a universidade, vamos querer caracterizar aquilo melhor no PDI. Então faz-se a revisão. Normalmente mexemos no PDI de dois em dois anos. Agora no planejamento estratégico, anualmente estamos mexendo nele.
\end{abstract}

Em todas as universidades há um órgão responsável pelo planejamento estratégico, geralmente um departamento de planejamento vinculado a uma pró-reitoria de planejamento. Apenas na Universidade Sigma, o órgão é vinculado ao gabinete do reitor. Entretanto, todos os entrevistados das universidades se preocuparam em dizer que o órgão apenas fornecia suporte e assessoramento, e não a elaboração dos documentos. $\mathrm{O}$ entrevistado 3 da Universidade Beta exara essa preocupação:

A própria coordenadoria de planejamento da universidade. A Pró-Reitoria de Planejamento. O PDI foi uma ação conjunta aberta dentro da universidade. A administração central centrou, fez um planejamento, um esqueleto básico do que deveria ser. Chamamos um especialista em planejamento, em PDI e planejamento 
estratégico. Orientou toda a classe, com a participação de docentes, discentes e técnico-administrativos, e depois fechamos esse PDI dentro do nosso Conselho Universitário. Então houve a participação de todos. Na verdade, naquele momento, foi a administração central, e eu fui o coordenador, eu como vice-reitor fui o coordenador, mas com a participação de todos. O que eu estou dizendo era uma coordenadoria, e hoje é uma Pró-Reitoria de Planejamento. É ela quem acompanha o que existe no PDI e no planejamento estratégico com o planejamento e ações de áreas dentro da universidade.

Considerando todos os casos analisados, percebe-se que não existe um modelo fixo de metodologia de condução do planejamento estratégico, bem como, nenhum dos entrevistados relatou proceder a pesquisa sob as orientações da administração por projetos. Todos os planejamentos são iniciados pela administração central, variando em suas conduções, mas em todas, necessitaram, ao final, de aprovação pela instância colegiada superior, por determinação de legislação.

Observa-se, entretanto, que os processos de elaboração dos planejamentos estudados caracterizam-se como atividades temporárias, com prazo de início e término, ou seja, não rotineiras, não repetitivas ou identificáveis como operações correntes. Acrescenta-se que a condução do processo temporário é realizado por uma equipe específica, geralmente com dedicação integral. Ambas as circunstâncias enquadram-se na ideia de Valeriano (2005) sobre administração de projetos.

\section{DISCUSSÕES E CONCLUSÕES}

Conforme os resultados apresentados, administração superior é responsável por conduzir o processo de planejamento das universidades analisadas, enquadrando esse tipo de planejamento como estratégico, por atender aos conceitos apresentados por Oliveira (2008), Pereira (2010) e Almeida (2010). A exigência de ser realizar planejamento oriunda de legislação, sendo que o MEC cobra das instituições o documento. Dessa forma, a concepção do projeto, de acordo com Valeriano (2005), é oriundo de entidade externa, sendo o MEC um dos clientes das instituições.

Os resultados indicam que a forma com que o processo de elaboração do planejamento estratégico é iniciado e finalizado, traz a ideia de administração de projetos, quando a comissão possui prazo de início e término de atuação, como afirmado por Lima (2010).

Em determinados casos, os membros da equipe que compõe a comissão pertencem a diversas áreas da instituição, como da graduação, pós-graduação, extensão, inovação e assuntos estudantis, atuando por tempo determinado na construção do planejamento, e 


\section{CONCILIANDO ADMINISTRAÇÃO DE PROJETOS E PLANEJAMENTO ESTRATÉGICO NA GESTÃO \\ DE UNIVERSIDADES FEDERAIS BRASILEIRAS \\ DOI: http://dx.doi.org/10.5007/10.5007/1983-4535.2014v7n3p93}

portanto, novamente corroborando com a ideia de administração de projeto. Ao dividir a comissão em subcomissões, o processo alinha-se à sugestão de Lima (2010) quando trata da Estrutura Analítica do Projeto, em decompor o projeto em partes menores, facilitando a execução da atividade como um todo.

O planejamento estratégico das universidades pesquisadas, quando analisados sob a perspectiva de projetos, apresenta diversos clientes, quando as ideias de Newton (2011) são rememoradas, desde os patrocinadores e financiadores, por ser exigência do MEC e do Reitor, a beneficiários e usuários finais, como os docentes, alunos e técnico-administrativo, e até o cliente final, que pode ser o Conselho Universitário, órgão que dá a aprovação final.

A participação no planejamento é recomendável tanto pelos autores de planejamento estratégico, quanto de administração de projetos, e em determinados casos, observou-se participação nula de alguns clientes, acarretando dificuldades na aprovação do documento final. Pode-se afirmar que houve deficiências no planejamento detalhado para se realizar o processo de elaboração do planejamento estratégico que deveria ser realizado, contrariando o que recomenda Valeriano (2005).

Observou-se que no geral, o planejamento estratégico elaborado não foi participativo, ficando restrito a alguns setores e pessoas, bem como seu modo de confecção visou atender a legislação, e assim, feito apressadamente, o que pode vir a prejudicar seu escopo, ao passo que apenas alguns setores foram consultados, havendo inclusive planejamentos realizados a partir de respostas de um questionário. Dessa forma, a principal deficiência observada foi de comunicação entre a equipe da comissão e os clientes, prejudicando a condução, ou os meios.

Pelo exposto, observa-se que não existe um único modelo de construção do planejamento estratégico, havendo uma customização à realidade de cada universidade. Há situações em que o processo é aberto a toda comunidade universitária, e em outros, restringese apenas aos gestores. Problemas de comunicação foram identificados, acarretando em prejuízos devido a baixa participação e consequente reprovação do documento elaborado pelo conselho superior.

Observa-se, entretanto, que a inicialização e término da elaboração do planejamento é semelhante entre as instituições, com a instauração de uma comissão plural no início e aprovação do documento final pelo Conselho Universitário, variando significativamente a condução da elaboração. Outra constatação é a decomposição do processo de elaboração em etapas, corroborando com os preceitos de Valeriano (2005). 
Dessa forma, conclui-se que os processos de elaboração dos planejamentos estratégicos não são realizados sob a ótica da administração de projetos, no entanto, determinadas etapas apresentam similaridades com o que é apresentado pelas teorias. No geral, o início e término do processo de elaboração do planejamento estratégico seguem os princípios da administração de projetos, no entanto, os meios deixam muito a desejar, o que parece causar rejeições após a finalização, podendo prejudicar a sua aceitação e implementação, como expõe Hrebiniak (2006).

Sugere-se, para fins de pesquisas futuras, que se estude maneiras de capacitar os condutores do processo de elaboração do planejamento estratégico em administração de projetos, visando assim, melhor efetividade em suas práticas.

\section{REFERÊNCIAS}

ALMEIDA, Martinho Isnard Ribeiro de. Manual de planejamento estratégico: desenvolvimento de um plano estratégico com a utilização de planilhas Excel. 3. ed. São Paulo: Atlas, 2010.

CERVO, Amado Luiz; BERVIAN, Pedro Alcino; SILVA, Roberto da. Metodologia científica. 6. ed. São Paulo: Pearson Prentice Hall, 2007.

CONSALTER, Maria Alce Soares. Elaboração de projetos: da introdução à conclusão. 3ed. Curitiba: Ibpex, 2011

COOPER, Donald R.; SCHINDLER, Pamela S. Métodos de pesquisa em administração. Tradução por Luciana de Oliveira da Rocha. 7. ed. Porto Alegre: Bookman, 2003.

CRUZ, Carla; RIBEIRO, Uirá. Metodologia científica: teoria e prática. Rio de Janeiro: Axcel Books, 2003.

DIEHL, Astor Antônio; TATIM, Denise Carvalho. Pesquisa em ciências sociais aplicadas: métodos e técnicas. São Paulo: Prentice Hall, 2004.

GIL, Antonio Carlos. Como elaborar projetos de pesquisa. 5. ed. São Paulo: Atlas, 2010.

HREBINIAK, Lawrence G. Fazendo a Estratégia Funcionar: o caminho para uma execução bem-sucedida. Porto Alegre: Bookman, 2006.

KLUYVER, Cornelis A. de; PEARCE II, John A. Estratégia: uma visão executiva. Tradução de Sônia Midori Tamamoto. Revisão técnica de Henrique Machado Barros. 3. ed. São Paulo: Pearson Prentice Hall, 2010.

LAKATOS, Eva Maria; MARCONI, Marina de Andrade. Metodologia científica. 5. ed. 4. reimpr. São Paulo: Atlas, 2010. 
LIMA, Rinaldo José Barbosa. Gestão de projetos. São Paulo: Pearson Education do Brasil, 2010

MAXIMIANO, Antonio Cesar Amaru. Teoria Geral da Administração. 1. ed. 11. reimpr. São Paulo: Atlas, 2012.

NEWTON, Richard. O gestor de projetos. São Paulo Pearson Prentice Hall, 2011.

OLIVEIRA, Djalma de Pinho Rebouças de. Planejamento estratégico: conceitos, metodologias e práticas. 25. ed. São Paulo: Atlas, 2008.

OLIVEIRA, Guilherme Bueno. Microsoft Project 2010 e gestão de projeto. Disponível em: <http://ufsc.bv3.digitalpages.com.br/users/publications/9788576059523/pages/_7>.

PEREIRA, Júlio Cesar R. Análise de dados qualitativos: estratégias metodológicas para as ciências da saúde, humanas e sociais. 3. ed. São Paulo: Editora da USP, 2004.

PEREIRA, Maurício Fernandes. Planejamento estratégico: teorias, modelos e processos. São Paulo: Atlas, 2010.

PMI, PROJECT MANAGEMENT INSTITUTE. O que é o PMI. 2014. Disponível em: <http://brasil.pmi.org/>. Acesso em: 11 jun. 2014.

SANTOS, Izequias Estevam dos. Manual de métodos e técnicas de pesquisa científica. 9. ed. rev. atual. e ampl. Niterói: Impetus, 2012.

SEVERINO, Antônio Joaquim. Metodologia do trabalho científico. 23. ed. ver. atual. São Paulo: Cortez, 2007.

VALERIANO, Dalton. Moderno gerenciamento de projetos. São Paulo: Prentice Hall, 2005. 